\title{
Home Office como instrumento de redução de custos: um estudo de caso realizado na empresa de logística Cargo Company - Recife/PE
}

\begin{abstract}
Antonia Dutra de Araujo Mestrado em Administração e Desenvolvimento Rural pela Universidade Federal Rural de Pernambuco Av. João Barros, 561. Recife/PE E-mail: araujo.antonia@globo.com

Antonio André Cunha Callado Doutorado em Administração pela Universidade Federal de Pernambuco - UFPE Rua Dom Manoel de Medeiros, s/n. Dois Irmãos/PE

E-mail: andrecallado@yahoo.com.br
\end{abstract}

\section{RESUMO}

O artigo tem como objetivo analisar os efeitos decorrentes da redução dos custos através da implantação do modelo Home Office na empresa Cargo Company. A metodologia aplicada na pesquisa tem como base duas etapas: na primeira etapa utilizou-se a técnica de entrevista com a direção e gestores da empresa, onde se coletou as variáveis qualitativas. Na segunda etapa aplicou-se um questionário semiestruturado, onde simultaneamente foram disponibilizados relatórios de desempenho com indicadores antes e depois da crise, ou seja, nesta fase se obteve dados quantitativos. É caracterizada como estudo de caso e foi realizada numa empresa de logística intermodal. Para respaldar a conclusão foi utilizado o método de análise de conteúdo e análise estrutural, com vistas a verificar os resultados da implantação do Home Office na redução dos custos. Foram utilizados dados das demonstrações contábeis, os quais foram analisados vertical e horizontalmente. A importância da realização do estudo dá-se em função da gestão inovadora incorporada pela empresa ao adotar o conceito Home Office como instrumento de redução de custos.

Palavras-chave: Custos. Análise de conteúdo. Análise estrutural. Home Office.

Home Office as a tool for cost reduction: a case study in a logystic company Cargo Company - Recife/PE

\section{ABSTRACT}

The article aims to analyze the effects of cost reduction through the implementation of the "Home Office" by Cargo Company. The methodology used in research is based on two steps: the first used the technique of interview with the director and managers of the company, which collected qualitative variables. In the later stage was applied semi- 
structured questionnaire, were both released reports on performance against indicators before and after the crisis, that is, at this stage to get quantitative data. It is characterized by the case study was conducted in a business and logistics integration. To support the conclusion was used the method of content analysis and structural analysis, where you can review the results of the implementation of the "Home Office" in cost reduction. Were used data from the financial statements and examined vertically and horizontally. The importance of the study is to incorporate the new management company to adopt the concept of "Home Office", as a tool for cost reduction.

Keywords: Costs. Content analysis. Structural analysis. Home Office.

\section{INTRODUÇÃO}

A logística é uma dessas áreas de atuação que se tornou fundamental no processo gerencial na política de importação e exportação. Segundo Carvalho (2002, p.31), a

logística é a parte do gerenciamento da cadeia de abastecimento que planeja, implementa e controla o fluxo e armazenamento eficiente e econômico de matérias-primas, materiais semi-acabados e produtos acabados, bem como informações relativas a empresa, desde o ponto de origem até o ponto de consumo, com o propósito de atender às exigências dos clientes.

De acordo com Ballou (1993), a logística empresarial estuda como a administração pode prover melhor nível de rentabilidade nos serviços de distribuição aos clientes e consumidores, através de planejamento, organização e controle efetivo para a atividade de movimentação e armazenagem, que visam facilitar o fluxo de produtos.

A logística no processo de distribuição é fundamental para os seus usuários, principalmente para o resultado final dos seus processos econômicos que buscam os melhores custos, eficiência no tempo, pois são estes fatores que influenciam na qualidade e na avaliação dos indicadores que balizam o nível de competitividade do mercado.

Dentro da área de atuação da logística, existe um importante ator denominado agente de cargas nacionais e/ou internacionais, cuja relevância é fundamental no 
Home Office como instrumento de redução de custos: um estudo de caso realizado na empresa de logística Cargo Company - Recife/PE Antonia Dutra de Araújo, Antonio André Cunha Callado

presente por dois fatores: a) o primeiro se refere à forma como busca prospectar o cenário mundial; e b) o segundo é expresso pela habilidade como conduz a negociação entre os exportadores, importadores e demais fornecedores de transportes intermodais.

Ballou (1993) comenta que a importância dessa classe está diretamente ligada a sua representatividade no processo de distribuição, pois o transporte é fator relevante, porque o frete pode absorver até dois terços dos gastos logísticos. Suas operações de consolidação de cargas são realizadas através do transporte intermodal, ou seja, são utilizados os meios rodoviário, ferroviário, hidroviário, marítimo e aéreo, conjugados ou separadamente.

Dados obtidos na Associação Brasileira de Movimentação e Logística (ABML) estimam que no Brasil os custos logísticos representam até $18 \%$ do PIB, cerca de 230 milhões de reais. No mercado norte americano, estes percentuais são de apenas $11 \%$, isto significa que o mercado pode ser expandido.

A principal preocupação do setor decorre da má qualidade do sistema brasileiro de transporte que termina por limitar o mercado aos arredores dos locais de produção, prejudicando o desenvolvimento econômico. É preciso maior agilidade na hora de programar a pauta de medidas para incrementar de forma qualitativa e quantitativa fatores que viabilizem a modernização do setor de transporte, favorecendo os setores de exportação e principalmente o de agronegócios e setores interligados.

Outro fator que vem desestabilizando este setor é a crise financeira mundial que afeta diretamente diferentes mercados, causando a desaceleração acentuada, principalmente no nível das relações comerciais das principais economias mundiais desde 2008. Como reflexo desta situação, alguns setores da economia sofrem com a diminuição do fluxo de demanda de serviços, ameaçando a permanência de muitas empresas.

Segundo Bastos (1999), os níveis de incerteza do mercado, cada vez mais elevados, e o dinamismo dos fatos, reflete no ambiente como um todo de forma crescente, que termina por ameaçar a sobrevivência das empresas.

Brandão e Guimarães (1999) comentam que este ambiente traz como conseqüência o desenvolvimento e a incorporação de novas tecnologias e modelo de 
Home Office como instrumento de redução de custos: um estudo de caso realizado na empresa de logística Cargo Company - Recife/PE Antonia Dutra de Araújo, Antonio André Cunha Callado

gestão. Para que ocorra esta evolução, as organizações devem buscar o melhoramento contínuo através do desenvolvimento das competências alinhado a utilização de ferramentas de gestão dos custos que lhes tornem capazes e aptas a competirem.

Diante da importância do setor e da fragilidade apresentada pelo mesmo neste momento de crise, chama a atenção a forma como a empresa examinada se comportou para superar o momento crítico. Daí a importância da realização do estudo, pois a mesma incorporou uma visão inovadora, cujo foco concentra-se na redução de custos, conciliada a um novo conceito de gestão denominado Home Office.

\section{REFERENCIAL TEÓRICO}

\subsection{Custos}

Os custos são de suma importância quando se trata do processo decisório de uma empresa, bem como todos os demais elementos integrantes de um gerenciamento que tem como objetivo o crescimento e a sobrevivência da instituição. Portanto, torna-se necessário uma abordagem teórica acerca dos conceitos de custos tradicionais como elemento primordial numa administração moderna que interage com os demais departamentos, com o intuito de obter informações gerenciais sobre todos os procedimentos que envolvem o negócio.

Para Martins (1998, p.25), "custo é gasto relativo à bem e/ou serviço utilizado na produção de outros bens e/ou serviços". Conforme Souza e Clemente (2007, p. 12), "os custos têm sido conceituados como o valor de todos os bens e serviços consumidos na produção de outros bens e serviços". Santos e Marion (1993, p. 35) "afirmam que custos são todos os gastos do processo de produção e criação, mão-de-obra, energia elétrica, desgaste das máquinas utilizadas para a produção, embalagem, etc".

Do ponto de vista de Santos e Marion (1993), os custos diretos podem ser identificados com precisão no produto acabado, utilizando-se um sistema ou um método de medição, cujo valor é relevante como: horas de mão-de-obra; quilos de sementes ou rações; gastos com funcionamento e manutenção de tratores. Os autores definem custos indiretos como aqueles necessários para a produção, normalmente de 
Home Office como instrumento de redução de custos: um estudo de caso realizado na empresa de logística Cargo Company - Recife/PE Antonia Dutra de Araújo, Antonio André Cunha Callado

mais de um produto, cuja alocação é arbitrária e efetuada por meio de um sistema de rateio, estimativa ou outro meio.

Ao se referir aos custos variáveis, Martins (2001) menciona que o valor total de consumo de materiais diretos por mês depende diretamente do volume de produção, pois quanto maior for a quantidade fabricada, maior será o seu consumo. Portanto, considerando uma unidade de tempo (mês, no exemplo), o custo com tais materiais varia de acordo com o volume de produção; significando que os materiais diretos são custos variáveis. Quanto ao custo fixo, o autor apresenta um exemplo de aluguel da fábrica em certo mês cujo valor é fixo, independentemente de aumentos ou diminuições naquele mês do volume elaborado de produtos. $O$ aluguel é, pois, um exemplo de custo fixo.

\subsection{Gestão de Custos}

$\mathrm{Na}$ visão empresarial a gestão de custos se destaca por agregar valor estratégico para competir no mercado. Hamilton (2004) define gestão de custos como um processo de estimativa, controle e análise de dados; como fonte geradora de

informações que continuamente alimenta as bases gerenciais. A gestão de custo é complexa e envolve três processos distintos: a estimação de custos (EC), a análise de variância de custos (AVC) e o feedback das informações de custos.

Niazi et al. (2007) definem a estimação de custos (EC) como sendo o processo que determina uma combinação de valores tangíveis e intangíveis, associados aos custos ocorridos, esperados ou inesperados, que os relacionam com algumas atividades realizadas na empresa. Os autores comentam que a estimação de custos (EC), quando feita de maneira correta, pode gerar ao processo uma eficiência e eficácia essencial nos casos em que o produto final seja um bem manufaturado, serviço ou ainda um projeto.

A metodologia mais usada para se obter a estimativa de custo, na visão de Dias Filho e Nakagawa (2001), consiste no estudo de engenharia industrial e na análise de dados históricos. No primeiro método leva-se em consideração projetos de produtos, volume de materiais consumidos na produção, entre outros insumos. Portanto, este 
Home Office como instrumento de redução de custos: um estudo de caso realizado na empresa de logística Cargo Company - Recife/PE Antonia Dutra de Araújo, Antonio André Cunha Callado

método tem como objetivo estabelecer relações físicas entre insumos produtivos e as saídas do processo (produtos acabados).

Ainda utilizando a argumentação do mesmo autor, este se refere ao método de estimação por análise de dados históricos, como aquele que busca fornecer estimativas de custos futuros, tendo como base as relações históricas dos períodos anteriores.

Fundamentando o pensamento anterior, Maher (2001) comenta que as estimativas passadas, de modo geral, poderão ser extremamente úteis quando comparadas com os custos ocorridos, no intuito de realizar um controle efetivo das variáveis passíveis de intervenções. O autor reforça a importância da análise da variância de custo (AVC), e conceitua dizendo que é uma comparação de preços e quantidades reais de insumo com respectivos padrões.

A análise quando feita em profundidade permite aos gestores identificar que 0 custo utilizado/estimado não é o ideal, favorecendo uma intervenção de forma a corrigilo. Na visão de Vanderbeck e Nagy (2001), a análise da variância de custo deve ser realizada, para que se possam realizar ações apropriadas de revisão ao perceber variações entre os custos esperados e os ocorridos.

O que ocorre no feedback das informações, é que normalmente as decisões são fundamentadas através do histórico de informações que irá contribuir em processos decisórios futuros. Normalmente são utilizadas para balizar e reforçar as decisões a serem tomadas, segundo Hamilton (2004). Cooper e Slagmulder (2004) defendem que os métodos de custeio e os sistemas de informações utilizados para gerenciar essas informações, de forma a alicerçar as decisões em âmbito gerencial, são normalmente fundamentados no retorno das informações (feedback).

$\mathrm{Na}$ era do conhecimento os sistemas de informações (SI) são ferramentas de suporte a gerência, e que estão atrelados ao processo de feedback. São utilizados em todas as etapas da gestão de custo, principalmente no processo de registro e armazenamento dos dados das transações, seus processamentos, e a geração dos relatórios com informações relevantes é fundamental para os gestores na hora da tomada de decisão. 
Home Office como instrumento de redução de custos: um estudo de caso realizado na empresa de logística Cargo Company - Recife/PE Antonia Dutra de Araújo, Antonio André Cunha Callado

Com a preocupação de se manter de forma sustentável e competitiva no mercado, as empresas miram a gestão de custo como um instrumento de gestão que estimula a geração de estratégias superiores, objetivando gerar vantagens competitivas sustentáveis. Segundo Shank e Govindarajan (1997, p. 4), "gestão estratégica de custos é uma análise de custos vista sobre um contexto amplo, cujos elementos estratégicos tornam-se mais conscientes, explícitos e formais".

\subsection{Custos de Logística}

Para se tratar de custo de logística, torna-se necessário antes comentar sobre a logística empresarial que é apontada como uma das formas mais rápidas e eficazes de se obter a minimização/redução dos custos operacionais e alavancar a competitividade das empresas (CHRISTOPHER, 1999).

Ao descrever o conceito de logística, deve-se ter o cuidado para não o descaracterizar. Pode-se dizer que o conceito básico relata que a matéria prima é transformada em produtos acabados. Este processo é visto como completo quando ocorre à finalização do ciclo. A fase inicial dá-se pelo acesso a matéria prima, percorrendo várias etapas de transformação e quando dado por concluído, este é deslocado para o mercado, chegando ao consumidor final. Esta operação é realizada mediante a busca e acesso a informações importantes e necessárias para a manutenção do nível de serviço fornecido aos clientes (BOWERSOX; CLOSS, 1999).

Este conceito apresenta pontos importantes relacionados a custo, considerandose que a logística empresarial é uma forma eficaz e veloz de minimizar custos operacionais, e que a eficácia do processo permite fortalecer a competitividade das empresas (CHRISTOPHER, 1999).

Segundo o Institute of Management Accountans - IMA (1992 apud FARIA, 2003), os custos logísticos são custos que devem ser gerenciados a partir do planejamento, implementação e controle de todo o inventário de entrada (inbound) e de saída (outbound), ou seja, devem ser controlados todos os custos envolvidos neste processo desde o ponto de origem até o ponto de consumo. 
Home Office como instrumento de redução de custos: um estudo de caso realizado na empresa de logística Cargo Company - Recife/PE Antonia Dutra de Araújo, Antonio André Cunha Callado

Sotkeviciene (2002), ao tratar dos custos de logística, identifica as características e custos específicos de cinco tipos de modais:

- Modal aéreo: é o que possui maior custo, entretanto é o que apresenta maior capacidade de reduzir o tempo de deslocamento do trajeto, garantindo entregas mais rápidas, disponibilidade e facilidade de rastreamento. É o mais adequado para atender as entregas emergenciais como, também, transportar produtos de alto valor unitário agregado. A escolha desta modalidade está ligada ao baixo índice de ocorrência de sinistros.

- Modal ferroviário: possui menor freqüência de saídas se comparado ao rodoviário. É economicamente eficaz na cobertura de grandes distâncias. Modal confiável, flexível e mais adequado para determinados tipos de produtos cujo valor agregado é baixo.

- Modal rodoviário: em termos de valor de capital é o que menos se aplica, se comparado com o ferroviário, e ainda oferece um serviço porta a porta, rápido e igualmente flexível, sendo mais indicado para volumes menores de carga.

- Modal marítimo: apesar de oferecer o menor custo por peso comparado com as distâncias percorridas, é o transporte mais lento entre os modais e não oferece um serviço porta a porta. Este tipo de modal é mais indicado para o deslocamento de grandes volumes de carga que podem aguardar o tempo de viagem para chegarem aos seus destinos.

- Modal hidroviário: é um transporte de menor custo, além de ser considerado ecologicamente correto. É um sistema de transporte privilegiado, comparado a outros, em relação ao meio ambiente físico e biótico, por ser de infra-estrutura natural. Em todos os países desenvolvidos, com condições ambientais para hidrovias, tem sido empregado, como nos Estados Unidos e países da União Européia, onde a rede hidroviária, em conjunto com ferrovias, é a base da matriz de transporte de matéria-prima agrícola e mineral.

O detalhamento e a identificação de custos de logística são fundamentais para o gerenciamento do setor de logística. Estes auxiliam na hora de fixar o nível máximo que 
Home Office como instrumento de redução de custos: um estudo de caso realizado na empresa de logística Cargo Company - Recife/PE Antonia Dutra de Araújo, Antonio André Cunha Callado

a empresa poderá reduzir em valores monetários os custos gerados na execução das atividades envolvidas no processo, sem que venha a prejudicar o padrão estabelecido dos serviços disponibilizados para os seus clientes.

Conceitualmente, Christopher (1996, p.57) define gerenciamento logístico como sendo um "conceito orientado para o fluxo, com o objetivo de integrar recursos ao longo de todo o trajeto que se estende desde os fornecedores até os clientes finais. É desejável que se tenha um meio de avaliar os custos e o desempenho deste fluxo".

Christopher (2001) em estudos posteriores afirma que um dos princípios básicos de custeio logístico, é que o sistema deve refletir o fluxo de materiais, ou seja, deve ser capaz de identificar os custos resultantes do fornecimento de serviço ao cliente. Comenta ainda que os custos logísticos devem possibilitar uma análise separada de custos e receitas, por tipo de cliente, segmento de mercado, e/ou canal de distribuição. Este último tem como objetivo tentar diminuir os riscos intrínsecos ao se realizar cálculos em que são usadas somente médias.

O detalhamento dos custos de logística também permite aos gestores identificar quanto irão precisar de receita adicional para aplicar em investimentos de melhorias do sistema, ou ainda, quanto necessitam para criar valor relacionado à qualidade dos serviços prestados pela empresa, e que sejam percebidos pelos clientes.

Segundo Christopher (2001), estes custos podem ser divididos em:

(a) custo operacional, que são todos aqueles diretamente relacionados à execução de uma atividade logística, e que sofrem variação de acordo com alterações do nível desta atividade. Estes custos se fazem presentes no cotidiano empresarial na medida em que são realizadas operações ligadas à logística. São custos com salários do pessoal, despesas de armazenagem, de embalagem e distribuição, e demais gastos referentes à realização das atividades logísticas.

(b) custos de capital, diferentemente dos custos operacionais, não estão diretamente ligados à quantidade ou ao nível de execução das atividades, mas sim, ao capital investido para realização das mesmas. Estes custos normalmente ocorrem a cada período de tempo pré-determinado, como o pagamento periódico de juros, distribuição de dividendos, distribuição de lucros aos acionistas e/ou proprietários. $\mathrm{O}$ 
Home Office como instrumento de redução de custos: um estudo de caso realizado na empresa de logística Cargo Company - Recife/PE Antonia Dutra de Araújo, Antonio André Cunha Callado

objetivo financeiro busca maximizar ao longo do tempo o resultado da receita anual menos os custos operacionais e de capital referentes ao sistema logístico.

Para Ballou (2001), os gestores têm como meta desenvolver um conjunto de atividades logísticas que resultem no maior retorno sobre o investimento ao longo do tempo. Para alcançar estas metas é necessário atingir duas dimensões que são: (1) o impacto do projeto do sistema logístico na contribuição para a receita e; (2) o custo do projeto do sistema logístico.

Vários esforços são realizados na busca de aumentar a visão do custo do fluxo logístico; e que terminam por criar ferramentas que auxiliam nesses aspectos. Outro fator importante para as empresas é definir qual é o melhor método a ser aplicado e qual é o foco da empresa (gerencial ou custos propriamente ditos).

Tem-se como exemplo de ferramentas utilizadas que tornam possível o gerenciamento por três diferentes aspectos que são (custos, produto e cliente), ou seja, Total Cost of Ownership - TCO, Customer Profitability Analysis - CPA e Direct Product Profitability - DPP.

\section{MÉTODO}

Quivy \& Campenhout (1992, p.41) mencionam que "a intenção dos pesquisadores não é só descrever, mas compreender o fenômeno de forma inteligível". Portanto, a metodologia adotada em pesquisas depende diretamente do objeto de estudo, de sua natureza, amplitude e dos objetivos do pesquisador.

\subsection{Caracterização da pesquisa}

Yin (2005) define estudo de caso como sendo uma pesquisa empírica, que investiga um fenômeno contemporâneo dentro de seu contexto real. Outro aspecto abordado pelo autor é que as fronteiras entre o fenômeno e o contexto não são claramente evidentes, além de utilizar múltiplas fontes de evidências.

O mesmo autor justifica através da sua aplicabilidade, a importância do estudo de caso, pois é através dele que é possível explicar ligações causais em intervenções ou 
Home Office como instrumento de redução de custos: um estudo de caso realizado na empresa de logística Cargo Company - Recife/PE Antonia Dutra de Araújo, Antonio André Cunha Callado

situações da vida real que são complexas demais para tratamento através de estratégias experimentais ou de levantamento de dados. Pode descrever um contexto de vida real no qual uma intervenção ocorreu, pode também avaliar uma intervenção em curso e modificá-la, com base em um estudo de caso ilustrativo, e por fim explorar aquelas situações nas quais a intervenção não tem clareza no conjunto de resultados.

O estudo de caso foi realizado em uma empresa de logística intermodal, que doravante adotará o nome fictício de Cargo Company, situada na região metropolitana do Recife/PE. É importante ressaltar que a realização da pesquisa só foi viável pela acessibilidade à empresa.

Segundo Mattar (1994), o estudo também pode ser caracterizado como pesquisa exploratória, pois ajuda o pesquisador a estabelecer as prioridades a estudar. $\mathrm{O}$ autor menciona que os métodos utilizados pela pesquisa exploratória são bastante amplos e versáteis e compreendem: levantamento em fontes secundárias, levantamento de experiências, observação informal e estudo de caso.

\subsection{Variáveis}

Os dados e as informações coletadas se deram por meio de variáveis qualitativas e quantitativas. Conforme Richardson et al. (1985), os estudos que empregam uma metodologia qualitativa podem descrever a complexidade de determinado problema, analisar a interação de certas variáveis, compreender e classificar processos dinâmicos vividos por grupos sociais.

Ainda para Richardson (1999, p. 70),

o método quantitativo, como o próprio nome indica, caracteriza-se pelo emprego da quantificação tanto nas modalidades de coleta de informações, quanto no tratamento delas por meio de técnicas estatísticas, desde as mais simples, como percentual, média, desvio-padrão, às mais complexas, como coeficiente de correlação, análise de regressão, etc. 
Home Office como instrumento de redução de custos: um estudo de caso realizado na empresa de logística Cargo Company - Recife/PE Antonia Dutra de Araújo, Antonio André Cunha Callado

\subsection{Coleta dos dados}

\subsubsection{Entrevista}

Para realizar a coleta de informações relevantes foi aplicada a técnica de entrevista informal semi-estruturada. De acordo com Triviños (1987), a entrevista semiestruturada parte de questionamentos básicos, apoiados em teorias e hipóteses que interessam à pesquisa. Em seguida oferecem amplo campo de interrogativas, junto de novas hipóteses que vão surgindo em função das respostas obtidas, de tal forma que o entrevistado, seguindo espontaneamente a linha de seu pensamento e de suas experiências dentro do foco principal colocado pelo investigador, começa a participar na elaboração do conteúdo da pesquisa.

$\mathrm{Na}$ visão de Hair et al. (2005), as entrevistas semi-estruturadas podem resultar no surgimento de informações inesperadas e esclarecedoras com um planejamento relativamente aberto, em contraposição à entrevista padronizada ou questionário. Torna-se possível observar como reagem os colaboradores a esta nova etapa, se ocorreu uma aceitação ou não.

A coleta de dados deu-se em duas fases. Na primeira fase da entrevista realizouse um levantamento histórico da empresa, através de conversas com os membros da diretoria. Este histórico relata como surgiu a empresa, como se concretizou, as parcerias, as oportunidades de novos mercados que viabilizaram o seu crescimento. $\mathrm{Na}$ segunda fase buscou-se coletar informações com os gerentes dos setores (comercial, operacional, recursos humanos e auxiliares administrativos), resultando na disponibilização de relatórios de desempenho do período antes da crise e após a reestruturação. Esta etapa viabilizou a compreensão de como foi idealizado e realizado o processo de implantação do Home Office. Criteriosamente as entrevistas possibilitaram ao entrevistador observar o ambiente in loco, direcionando o foco de observação para o fluxo de atividades.

Tedlock (2005) narra que nesta técnica de observação o pesquisador acompanha o comportamento das pessoas e desenvolve conversações com alguns ou todos participantes que vivenciam ou tem experiência com o problema, captando a opinião individualizada de cada indivíduo sobre o acontecimento observado. 
Home Office como instrumento de redução de custos: um estudo de caso realizado na empresa de logística Cargo Company - Recife/PE Antonia Dutra de Araújo, Antonio André Cunha Callado

\subsubsection{Pesquisa documental}

$\mathrm{Na}$ concepção de Bardin (2002), a pesquisa documental pode ser realizada a partir das fontes de informação contidas em registros documentais na forma tradicional ou em meio magnético.

A empresa disponibilizou planilha de custos, porém para efeito de análise do estudo de caso estes valores são fictícios, porém possibilitando gerar uma simulação do que seria o ambiente real. Também foi disponibilizado o organograma funcional da empresa antes e depois da crise, entre outros, que foram liberados por e-mail através de arquivos eletrônicos. Estas documentações deram respaldo aos dados coletados na entrevista sobre o histórico e crescimento da empresa. A Cargo Company não forneceu os planos de conta de São Paulo e Belém, sendo apenas disponibilizados os de Recife, Fortaleza e Salvador.

\subsection{Método de análise}

Como método de análise tem-se:

(1) Análise de conteúdo: tratam-se de etapas a serem seguidas num determinado processo, que inclui uma análise de documentos, relatórios, narrativas, etc., que são interpretados pelos indivíduos envolvidos no processo investigativo.

A análise pode avaliar o contéudo por duas perspectivas que são quantitativa e qualitativa. Se caracteriza por analisar numericamente a frequência de ocorrência de determinados termos, construções e referências em um dado texto. Dentro da visão da ciência da comunicação, é frequentemente usada como contraponto à análise da entrevista, que expressa o pensamento em forma de discurso eminentemente qualitativa.

(2) Análise estrutural (vertical e horizontal): antecipadamente se faz necessário conhecer o conceito da análise das demonstrações contábeis, que segundo Marion (2009), é a técnica contábil em que se decompõe, compara e interpreta as demonstrações contábeis.

Dentro da análise das demonstrações contábeis são utilizados os seguintes processos: (a) análise vertical, (b) análise horizontal, e (c) análise por quocientes. No 
Home Office como instrumento de redução de custos: um estudo de caso realizado na empresa de logística Cargo Company - Recife/PE Antonia Dutra de Araújo, Antonio André Cunha Callado

estudo foram utilizados os processos (a) e (b) para o mês de janeiro de 2008 e 2009, caracterizando o intervalo de um ano.

\section{APRESENTAÇÃO E ANÁLISE DOS DADOS}

\subsection{Histórico da Empresa}

A Cargo Company é uma sociedade limitada, com capital totalmente pernambucano, fundada em outubro de 1997, classificada como empresa de pequeno porte - EPP. Tem, conforme contrato social o seguinte objetivo: prestação de serviços no atendimento, auxílio e apoio na organização de transportes comercial marítimo, aéreo, rodoviário e ferroviário, nacional e internacional, consolidação e desconsolidação de cargas aéreas, marítimas, rodoviárias e ferroviárias.

A empresa iniciou as atividades com o contrato de supervisão da logística interna do Sistema de telefonia celular "Banda B" para a região 10, cobrindo os Estados de Alagoas, Pernambuco, Paraíba, Rio Grande do Norte, Ceará e Piauí, no ano de 1998.

No término desta empreitada houve um redirecionamento das atividades por parte dos sócios, estes remanescentes de empresas do ramo de transporte e terminal marítimo, somaram suas experiências e começaram a atuar na organização e logística de transporte aéreo e marítimo internacional, atendendo aos mercados alagoano, pernambucano, paraibano e potiguar.

Em Maio de 1999 foi fechado um acordo de agenciamento com a J.H Bachmann $\mathrm{GmbH}$ em Bremen na Alemanha, um dos mais tradicionais consolidadores de cargas do país, com quem a Cargo Company até hoje mantêm relações de cooperação com todos os países onde esta empresa se encontra instalada.

Em setembro de 2000 os proprietários decidiram expandir o seu mercado para o Norte, fundando a sua primeira filial em Fortaleza/CE, a Cargo Company do Ceará Ltda, que cobriria desde o mercado cearense até o maranhense. Dois meses após este fato a empresa, sentindo a necessidade de ampliar sua estrutura inaugurou a sua segunda filial agora em salvador/BA, cujo campo de atuação cobriria todo o estado da Bahia até 
Sergipe, atingindo assim a meta de cobertura estipulada para o ano de 2000, que objetivava atingir todo nordeste brasileiro.

Visando melhorias na qualidade, a empresa obteve o certificado de Qualidade Internacional ISO 9002 da certificadora alemã DQS (Deutsche Qualitäts Systeme), tornando-se assim, o primeiro agente de carga do Nordeste do Brasil portador deste certificado.

Ainda na fase de abertura de mercado, a Cargo Company enfrentou um novo desafio, inaugurava em 2004 a filial de São Paulo capital e o escritório de apoio na cidade de Belém, no Estado do Pará. Geograficamente a empresa se colocou em pontos estratégicos, ampliando o campo de atuação e atendendo a demanda de mercado das regiões Norte, Nordeste e Sudeste, ficando responsável por abranger as cidades do Sul do Brasil.

A expansão trouxe novos desafios e alguns obstáculos gerenciais a serem superados. Diante dessas novas necessidades, a Cargo Company reavaliou a sua estrutura e reformulou o seu organograma, conforme figura 1. 
Home Office como instrumento de redução de custos: um estudo de caso realizado na empresa de

logística Cargo Company - Recife/PE

Antonia Dutra de Araújo, Antonio André Cunha Callado

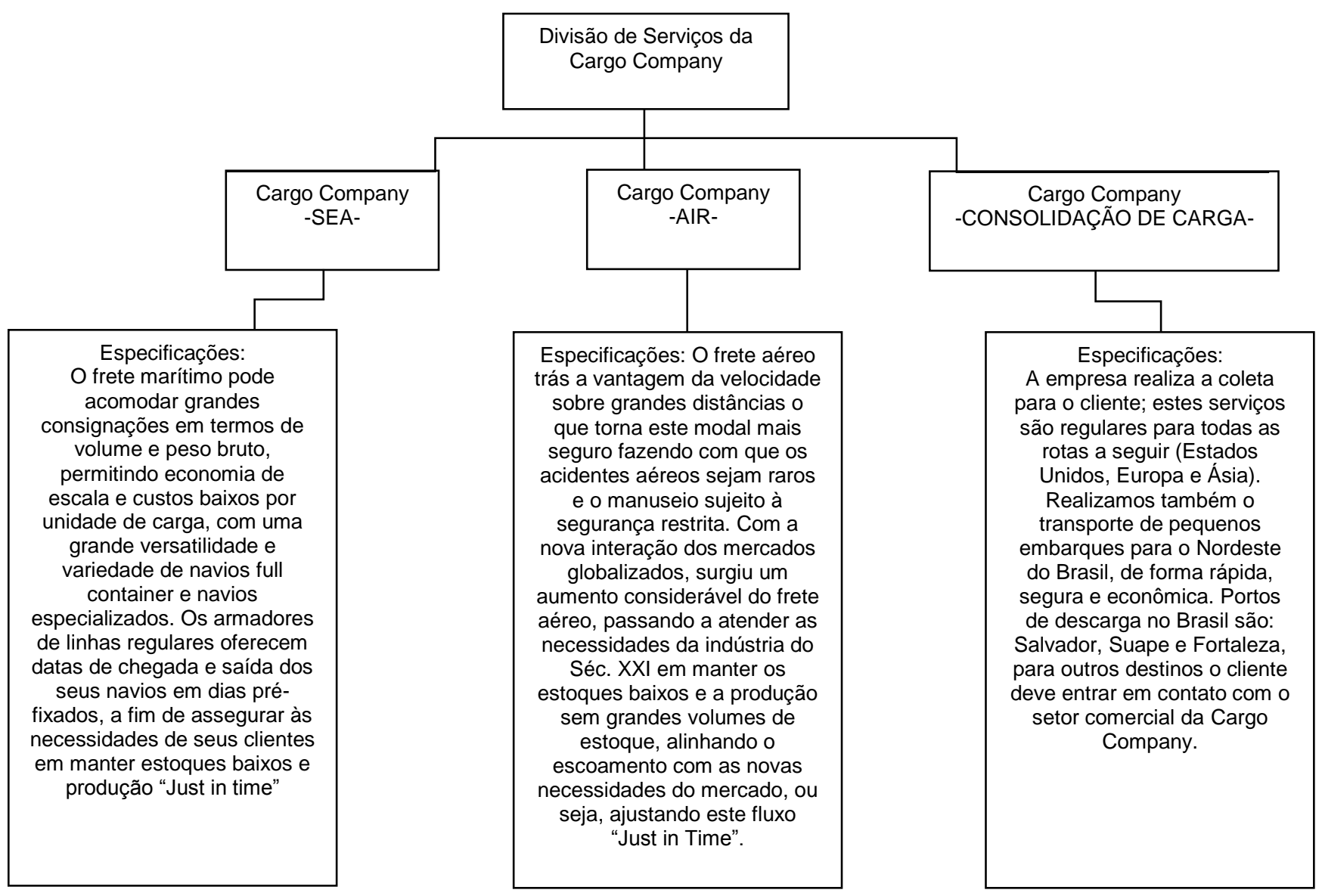

Figura 1 - Divisão de Serviços por Segmentação

Fonte: Dados fornecidos pela empresa.

O dirigente da Cargo Company entrevistado informa que esta possui dois sócios e dezesseis parceiros distribuídos pela Europa, Ásia, EUA, África, America do Sul (Chile, Argentina e Uruguai). Os principais concorrentes são Panalpina, Kuehne+Nagel e Eagle Global Logistics.

A empresa dispõe de um diferencial marcante em relação aos concorrentes, utiliza a gestão de marketing de rede, segundo os gestores consultados, personaliza o atendimento a cada cliente atendendo com exclusividade a demanda dos mesmos.

A empresa possui um CRM- Customer Relationship Management. Segundo o gestor de marketing da empresa, esta visão permite trabalhar estrategicamente junto aos parceiros de forma competitiva. Esta reformulação em relação ao macro ambiente surgiu da crescente necessidade de alcançar vantagem competitiva, o que influenciou o 
Home Office como instrumento de redução de custos: um estudo de caso realizado na empresa de logística Cargo Company - Recife/PE Antonia Dutra de Araújo, Antonio André Cunha Callado

ambiente interno na busca de elementos inovadores que foram supridos por novas teorias sobre o relacionamento com o cliente.

O cliente desempenha hoje um papel especial no contexto organizacional e o CRM (Customer Relationship Management) tem sido utilizado como ferramenta de posicionamento no mercado. Posicionamento focado no valor agregado e a redução dos riscos de perda, que envolve esta relação cliente e empresa, aspectos que constituem os principais objetivos do CRM (RYALS, 2002a).

Ainda durante a entrevista foi mencionado que a Cargo Company identifica claramente os atributos do serviço que agregam valor ao cliente e que são capazes de gerar fidelidade. Outro ponto considerado fundamental para a Cargo Company é conhecer a cultura de cada região, para trabalhar o mercado utilizando o geomarketing, - que facilita entender o funcionamento de diversas variáveis existentes especificamente em cada região, trabalhando-as a favor da empresa na hora de atender os clientes.

No caso de Pernambuco, a direção da empresa fala com orgulho de ser a primeira empresa do Estado a atuar no segmento de Logística Internacional e também a primeira a receber a certificação ISO 9001:2000 no Nordeste.

No setor comercial se obteve o detalhamento de uma das atividades executada por esta célula. O comercial visita o cliente importador ou exportador, faz-se apresentação da empresa, coleta todos os dados do cliente, isto é: mercadoria, valor, tipo do equipamento a ser utilizado, destino, incoterm (regras para o comercio internacional que o comprador e vendedor devem ter), etc.

Este processo pode ser elaborado por meio digital ou posteriormente, onde de volta ao escritório o colaborador elabora via sistema a proposta informando todos os detalhes do transporte e envia por e-mail ao cliente. Sendo aprovada a proposta pelo cliente, a empresa contata o seu parceiro no local de origem do fornecedor, o qual já se apresenta como representante da Cargo Company, e que está autorizado pelo comprador da mercadoria (isto no caso da importação). O parceiro organiza a coleta da mercadoria, providencia o transporte (marítimo ou aéreo) e informa todos os dados para a Cargo Company. 
A partir daí a Cargo Company acompanha através de sistema de satélite o transporte dando todas as informações para o cliente, a fim de que o mesmo providencie com o seu despachante aduaneiro a liberação da carga quando chegar ao destino.

\subsection{Análise dos Resultados}

A empresa Cargo Company sofreu no segundo semestre de 2008 uma acentuada redução no volume de carga exportada e importada, por parte dos seus clientes. Esta redução repercutiu diretamente no faturamento da empresa, gerando uma instabilidade. Assim, houve necessidade de introduzir uma política de redução de custos de forma a reverter os impactos decorrentes da crise. A intervenção se deu, a princípio, através de uma re-estruturação e realinhamento dos espaços físicos da matriz e filiais com a introdução do modelo Home Office e redução de custos. Os diretores se mostraram ousados quando introduziram juntamente com a redução de custos, o novo conceito de serviço Home office, que repercutiu diretamente na estrutura, ao decidir que o melhor no momento era a eliminação dos custos. Estas medidas foram tomadas logo após serem sentidos os primeiros efeitos da crise, com uma desestabilização financeira que exigiu dos gestores medidas em caráter de urgência.

Por Home Office compreende-se um modelo de trabalho flexível, que nasceu das alterações e transformações ocorridas no mercado de trabalho. Este modelo é resultado do avanço tecnológico que possibilitou integrar pessoas de forma virtual, quebrando as barreiras geográficas e ampliando as relações comerciais (SEBRAE, 2002).

Os custos e faturamento informados pela empresa constam na Tabela 1 (estimativa de valores antes da crise). 
Home Office como instrumento de redução de custos: um estudo de caso realizado na empresa de logística Cargo Company - Recife/PE Antonia Dutra de Araújo, Antonio André Cunha Callado

Tabela 1 - estimativa de valores (Antes da Crise)

\begin{tabular}{|c|c|c|c|c|c|}
\hline $\begin{array}{c}\text { ANTES DA } \\
\text { CRISE }\end{array}$ & Faturamento & Custos & $\%$ & Custos & $\%$ \\
\hline $\mathbf{2 0 0 8}$ & $\begin{array}{c}\text { Anual } \\
\text { (plano) }\end{array}$ & Administrativo & & Operacionais & \\
\hline $\begin{array}{c}\text { Matriz --> } \\
\text { REC }\end{array}$ & $620.000,00$ & $540.000,00$ & 51,72 & $56.000,00$ & 52,83 \\
\hline Filial FOR & $210.000,00$ & $180.000,00$ & 17,24 & $18.000,00$ & 16,98 \\
\hline Filial SSA & $80.000,00$ & $72.000,00$ & 6,90 & $7.000,00$ & 6,60 \\
\hline Filial BEL & $80.000,00$ & $72.000,00$ & 6,90 & $7.000,00$ & 6,60 \\
\hline Filial SPO & $\underline{210.000,00}$ & $\underline{180.000,00}$ & $\underline{17,24}$ & $\underline{18.000,00}$ & $\underline{16,98}$ \\
\hline & $1.200 .000,00$ & $1.044 .000,00$ & 100,00 & $106.000,00$ & 100,00 \\
\hline & & \multicolumn{5}{|c|}{ LUCRO } \\
& ESTIMADO ---> & & $\mathbf{5 0 . 0 0 0 , 0 0}$ & \\
\hline
\end{tabular}

Fonte: Dados fornecidos pela empresa.

O valor da receita bruta de $\mathrm{R} \$ 1,2$ milhões se refere a $10 \%$ do montante correspondente ao recebimento fretes.

O faturamento da matriz de Recife relacionado com o custo administrativo revela que estes custos absorveram $87,09 \%$ do valor do faturamento, e a absorção do custo operacional corresponde a $9,03 \%$ da receita. Somando-se o percentual dos custos administrativos com o custo operacional, tem-se um montante de $96,12 \%$. Deduzindose este percentual da receita da matriz Recife, é possível identificar quanto a empresa teve de lucro realizável no ano de 2008 para Recife da ordem de 3,88\%.

$\mathrm{Na}$ filial de Fortaleza os custos administrativos representaram $85,70 \%$ da receita do faturamento, quando os custos operacionais correspondiam a $8,57 \%$. A soma de $94,27 \%$ deduzida do total do faturamento mostra que esta filial obteve $5,73 \%$ de lucratividade.

Salvador e Belém apresentaram os mesmos índices, portanto, os resultados obtidos se aplicam para ambas as filiais, ou seja, uma lucratividade correspondente a $0,28 \%$.

A projeção de valores para o ano de 2009 (depois da crise) pode ser visualizada na Tabela 2. 
Home Office como instrumento de redução de custos: um estudo de caso realizado na empresa de logística Cargo Company - Recife/PE Antonia Dutra de Araújo, Antonio André Cunha Callado

Tabela 2 - Projeção de valores para o ano de 2009 (Depois da Crise)

\begin{tabular}{|c|c|c|c|c|c|}
\hline $\begin{array}{c}\text { DEPOIS DA } \\
\text { CRISE }\end{array}$ & $\begin{array}{c}\text { Faturamento } \\
\text { Anual } \\
\text { (plano) }\end{array}$ & Custos & $\%$ & Custos & $\%$ \\
\hline $\begin{array}{c}\text { Matriz --> } \\
\text { REC }\end{array}$ & $580.000,00$ & $540.000,00$ & 79,65 & $40.000,00$ & 100,00 \\
\hline Filial FOR & $25.000,00$ & $30.000,00$ & 4,42 & - & - \\
\hline Filial SSA & $25.000,00$ & $30.000,00$ & 4,42 & - & - \\
\hline Filial BEL & $25.000,00$ & $30.000,00$ & 4,42 & - & - \\
\hline Filial SPO & $\underline{65.000,00}$ & $\underline{48.000,00}$ & $\underline{7,08}$ & - & - \\
\hline & $720.000,00$ & $678.000,00$ & 100,00 & $40.000,00$ & 100,00 \\
\hline & & $\begin{array}{c}\text { LUCRO } \\
\text { ESTIMADO ---> }\end{array}$ & & $\mathbf{2 . 0 0 0 , 0 0}$ & \\
\hline
\end{tabular}

Fonte: Dados fornecidos pela empresa.

O montante estimado de $\mathrm{R} \$ 7.200 .000,00$ refere-se ao recebimento Fretes. Deste valor deduz-se $10 \%$, resultando na quantia de $\mathrm{R} \$ 720.000,00$ correspondem à receita bruta para o ano de 2009. Segundo o diretor consultado, o faturamento 2009 tende a sofrer uma redução de $40 \%$ em relação ao período de 2008 . Considerando esta redução, a projeção de lucro é de $R \$ 2.000,00$

A projeção pode sofrer alterações à medida que a implantação se concretizar, pois, haverá uma extinção dos custos das filiais de São Paulo, Belém, Fortaleza e Salvador. A conclusão está prevista para o final de maio de 2009. Significa que o fechamento legal e a realocação da mão-de-obra terão sido efetuados, além de realizar o pagamento dos credores a curto e médio prazo, o que gerará um resíduo que se estenderá até novembro de 2009.

Quanto ao aumento das exportações, esta variável dependerá do comportamento do mercado mundial diante da crise, sendo que a receita da empresa oscilará em conformidade com o consumo do mercado nacional e internacional.

A análise horizontal compreendendo o período de janeiro 2008 e janeiro 2009 da Matriz Recife, assim se apresenta: 
Home Office como instrumento de redução de custos: um estudo de caso realizado na empresa de logística Cargo Company - Recife/PE Antonia Dutra de Araújo, Antonio André Cunha Callado

Tabela 3 - Análise Horizonte da Matriz Recife - período Janeiro 2008/2009

\begin{tabular}{|c|c|c|c|c|}
\hline $\begin{array}{c}\text { ANÁLISE HORIZONTAL } \\
\text { PLANO DE CONTAS }\end{array}$ & $\begin{array}{c}\text { RECIFE - REC } \\
\text { JAN - 2008 } \\
\text { Valor Absoluto }\end{array}$ & AH & $\begin{array}{c}\text { RECIFE - REC } \\
\text { JAN - 2009 } \\
\text { Valor Absoluto }\end{array}$ & AH (\%) \\
\hline 01.00 - PESSOAL & $42.583,64$ & 100 & $\mathbf{4 6 . 9 9 5 , 3 5}$ & $\mathbf{1 1 0 , 3 6}$ \\
\hline $\begin{array}{c}\text { 02.00 - SERVIÇOS E } \\
\text { ASSESSORIAS }\end{array}$ & $4.256,40$ & 100 & $\mathbf{5 . 2 4 3 , 7 3}$ & $\mathbf{1 2 3 , 2 0}$ \\
\hline $\mathbf{0 3 . 0 0 ~ - ~ I M P O S T O S ~ E ~ T A X A S ~}$ & $5.577,41$ & 100 & $\mathbf{3 . 6 6 1 , 6 6}$ & $\mathbf{6 5 , 6 5}$ \\
\hline $\begin{array}{c}\text { 04.00 - DESPESAS } \\
\text { ESCRITÓRIO }\end{array}$ & $4.447,78$ & 100 & $\mathbf{4 . 2 9 9 , 9 8}$ & $\mathbf{9 6 , 6 8}$ \\
\hline $\mathbf{0 5 . 0 0 ~ - ~ C O M U N I C A C ̧ A ̃ O ~}$ & $3.074,89$ & 100 & $\mathbf{2 . 2 5 0 , 8 0}$ & $\mathbf{7 3 , 2 0}$ \\
\hline $\mathbf{0 6 . 0 0}$ - DESP. FINANCEIRAS & 298,00 & 100 & $\mathbf{1 5 . 9 6 4 , 3 9}$ & $\mathbf{5 3 5 7 , 1 8}$ \\
\hline $\mathbf{0 7 . 0 0 ~ - ~ P R O P A G A N D A ~}$ & 318,00 & 100 & $\mathbf{2 6 0 , 0 0}$ & $\mathbf{8 1 , 7 6}$ \\
\hline $\mathbf{0 8 . 0 0 ~ - ~ A D M I N I S T . ~ D I V E R S A S ~}$ & $3.605,02$ & 100 & $\mathbf{9 2 5 , 9 4}$ & $\mathbf{2 5 , 6 8}$ \\
\hline $\mathbf{0 9 . 0 0 ~ - ~ R E P R E S E N T A C ̧ O ̃ E S ~}$ & 320,62 & 100 & $\mathbf{1 7 6 , 9 3}$ & $\mathbf{5 5 , 1 8}$ \\
\hline $\mathbf{1 1 . 0 0}$ - VEÍCULOS & $5.891,06$ & 100 & $\mathbf{5 . 4 8 1 , 4 9}$ & $\mathbf{9 3 , 0 5}$ \\
\hline TOTAIS & $\mathbf{7 0 . 3 7 2 , 8 2}$ & $\mathbf{1 0 0}$ & $\mathbf{8 5 . 2 6 0 , 2 7}$ & $\mathbf{1 2 1 , 1 6}$ \\
\hline
\end{tabular}

Fonte: Dados fornecidos pela empresa.

$\mathrm{Na}$ análise horizontal é possível observar que em janeiro de 2009 as despesas com pessoal excedem em 10,36\% o valor de 2008, resultando do pagamento da segunda parcela do $13^{\text {o }}$ salário realizado em dezembro de 2008. As despesas com serviços e assessorias também teve acréscimo de $23,2 \%$ e as despesas financeiras apresentam um aumento extraordinário de mais de $5.200 \%$.

A análise horizontal da Filial Fortaleza assim se apresenta: 
Home Office como instrumento de redução de custos: um estudo de caso realizado na empresa de logística Cargo Company - Recife/PE Antonia Dutra de Araújo, Antonio André Cunha Callado

Tabela 4 - Análise Horizontal do mês de janeiro de 2008 e 2009 referente à Filial Fortaleza

\begin{tabular}{|c|c|c|c|c|}
\hline $\begin{array}{l}\text { ANÁLISE HORIZONTAL } \\
\text { PLANO DE CONTAS }\end{array}$ & $\begin{array}{c}\text { FORTALEZA - FOR } \\
\text { Jan - } 2008 \\
\text { Valor Absoluto }\end{array}$ & $\mathbf{A H}$ & $\begin{array}{c}\text { FORTALEZA - } \\
\text { FOR } \\
\text { Jan - } 2009 \\
\text { Valor Absoluto }\end{array}$ & $\mathbf{A H}$ \\
\hline 01.00 - PESSOAL & $14.411,51$ & 100 & $5.517,66$ & 38,29 \\
\hline $\begin{array}{c}02.00 \text { - SERVIÇOS E } \\
\text { ASSESSORIAS }\end{array}$ & 766,50 & 100 & 750,00 & 97,85 \\
\hline $\begin{array}{c}03.00 \text { - IMPOSTOS E } \\
\text { TAXAS }\end{array}$ & $2.472,91$ & 100 & $1.591,79$ & 64,37 \\
\hline $\begin{array}{l}04.00 \text { - DESPESAS } \\
\text { ESCRITÓRIO }\end{array}$ & $1.885,33$ & 100 & $2.108,11$ & 111,82 \\
\hline 05.00 - COMUNICAÇÃO & $1.274,81$ & 100 & 971,40 & 76,20 \\
\hline $\begin{array}{l}06.00 \text { - DESP. } \\
\text { FINANCEIRAS }\end{array}$ & 67,00 & 100 & 66,00 & 98,51 \\
\hline 07.00 - PROPAGANDA & & 100 & & \\
\hline $\begin{array}{c}08.00 \text { - ADMINIST. } \\
\text { DIVERSAS }\end{array}$ & 988,50 & 100 & 453,80 & 45,91 \\
\hline $\begin{array}{c}09.00- \\
\text { REPRESENTAÇÕES }\end{array}$ & 379,19 & 100 & & 0,00 \\
\hline 11.00 - VEÍCULOS & & 100 & & \\
\hline TOTAIS & $22.245,75$ & 100 & $11.458,76$ & 51,51 \\
\hline
\end{tabular}

Fonte: Dados fornecidos pela empresa.

Examinando-se os valores apresentados na Tabela 4, observa-se uma redução de cerca de 50\% nas despesas de 2008 para 2009 na Filial de Fortaleza. Estes dados correspondem ao período em que a filial encerra legalmente as suas funções no Estado. Os serviços da filial ao término da dissolução são absorvidos pela matriz em Recife e o funcionário da filial foi transferido para a folha de pagamento da matriz, porém irá trabalhar no regime Home Office em Fortaleza.

A análise horizontal referente janeiro 2008 e janeiro 2009 da filial de Salvador assim se apresentam: 
Home Office como instrumento de redução de custos: um estudo de caso realizado na empresa de logística Cargo Company - Recife/PE Antonia Dutra de Araújo, Antonio André Cunha Callado

Tabela 5 - Análise Horizontal do mês de janeiro de 2008 e 2009 referente à Filial Salvador

\begin{tabular}{|c|c|c|c|c|}
\hline $\begin{array}{l}\text { ANÁLISE HORIZONTAL } \\
\text { PLANO DE CONTAS }\end{array}$ & $\begin{array}{c}\text { SALVADOR - SSA } \\
\text { jan -2008 } \\
\text { Valor Absoluto }\end{array}$ & $\mathbf{A H}$ & $\begin{array}{c}\text { SALVADOR - SSA } \\
\text { Jan -2009 } \\
\text { Valor Absoluto }\end{array}$ & $\mathbf{A H}$ \\
\hline 01.00 - PESSOAL & $4.921,84$ & 100 & $1.928,86$ & 39,19 \\
\hline $\begin{array}{l}02.00 \text { - SERVIÇOS E } \\
\text { ASSESSORIAS }\end{array}$ & 505,00 & 100 & 380,00 & 75,25 \\
\hline $\begin{array}{c}03.00 \text { - IMPOSTOS E } \\
\text { TAXAS }\end{array}$ & & 100 & 0,17 & \\
\hline $\begin{array}{c}04.00 \text { - DESPESAS } \\
\text { ESCRITÓRIO }\end{array}$ & $1.158,69$ & 100 & & 0,00 \\
\hline 05.00 - COMUNICAÇÃO & 430,31 & 100 & 338,71 & 78,71 \\
\hline $\begin{array}{l}06.00 \text { - DESP. } \\
\text { FINANCEIRAS }\end{array}$ & & 100 & 76,00 & \\
\hline 07.00 - PROPAGANDA & & 100 & & \\
\hline $\begin{array}{c}\text { 08.00 - ADMINIST. } \\
\text { DIVERSAS }\end{array}$ & & 100 & & \\
\hline $\begin{array}{c}09.00- \\
\text { REPRESENTAÇÕES }\end{array}$ & & 100 & & \\
\hline 11.00 - VEÍCULOS & $1.191,90$ & 100 & & 0,00 \\
\hline TOTAIS & $8.207,74$ & 100 & $2.723,74$ & 33,19 \\
\hline
\end{tabular}

Fonte: Dados fornecidos pela empresa.

Esta filial está em processo de encerramento das suas atividades no Estado da Bahia, daí apresentar o fluxo do resultado da análise com variação negativa para todas as contas ainda existentes, absorvidas pela matriz definitivamente em junho de 2009. Nesta data tem início o sistema Home Office, também nesta filial.

Aplicando-se os procedimentos de análise vertical antes da crise (2008) na matriz de Recife e filiais de Fortaleza e Salvador, tem-se: 
Home Office como instrumento de redução de custos: um estudo de caso realizado na empresa de logística Cargo Company - Recife/PE Antonia Dutra de Araújo, Antonio André Cunha Callado

Tabela 6 - Análise Vertical do mês de janeiro 2008 - (Recife, Fortaleza e Salvador)

\begin{tabular}{|c|c|c|c|c|c|c|}
\hline $\begin{array}{l}\text { ANTES DA CRISE } \\
\text { ANÁLISE VERTICAL } \\
\text { PLANO DE CONTAS }\end{array}$ & $\begin{array}{c}\text { RECIFE - } \\
\text { REC } \\
\text { Jan - } 2008 \\
\text { Valor } \\
\text { Absoluto } \\
\end{array}$ & AV & $\begin{array}{l}\text { FORTALEZA - } \\
\text { FOR Jan - } \\
2008 \\
\text { Valor Absoluto }\end{array}$ & AV & $\begin{array}{c}\text { SALVADOR - } \\
\text { SSA Jan - } \\
2008 \\
\text { Valor Absoluto }\end{array}$ & AV \\
\hline 01.00 - PESSOAL & $42.583,64$ & 60,51 & $14.411,51$ & 64,78 & $4.921,84$ & 59,97 \\
\hline $\begin{array}{l}02.00 \text { - SERVIÇOS E } \\
\text { ASSESSORIAS }\end{array}$ & $4.256,40$ & 6,05 & 766,50 & 3,45 & 505,00 & 6,15 \\
\hline $\begin{array}{c}03.00 \text { - IMPOSTOS E } \\
\text { TAXAS }\end{array}$ & $5.577,41$ & 7,93 & $2.472,91$ & 11,12 & & 0,00 \\
\hline $\begin{array}{l}04.00 \text { - DESPESAS } \\
\text { ESCRITÓRIO }\end{array}$ & $4.447,78$ & 6,32 & $1.885,33$ & 8,48 & $1.158,69$ & 14,12 \\
\hline $\begin{array}{c}05.00 \text { - } \\
\text { COMUNICAÇÃO }\end{array}$ & $3.074,89$ & 4,37 & $1.274,81$ & 5,73 & 430,31 & 5,24 \\
\hline $\begin{array}{l}06.00 \text { - DESP. } \\
\text { FINANCEIRAS }\end{array}$ & 298,00 & 0,42 & 67,00 & 0,30 & & 0,00 \\
\hline $\begin{array}{c}07.00- \\
\text { PROPAGANDA }\end{array}$ & 318,00 & 0,45 & 0,00 & 0,00 & & 0,00 \\
\hline $\begin{array}{c}\text { 08.00 - ADMINIST. } \\
\text { DIVERSAS }\end{array}$ & $3.605,02$ & 5,12 & 988,50 & 4,44 & & 0,00 \\
\hline $\begin{array}{c}09.00 \text { - } \\
\text { REPRESENTAÇÕES }\end{array}$ & 320,62 & 0,46 & 379,19 & 1,70 & & 0,00 \\
\hline 11.00 - VEÍCULOS & $5.891,06$ & 8,37 & 0,00 & 0,00 & $1.191,90$ & 14,52 \\
\hline TOTAIS & $70.372,82$ & 100,00 & $22.245,75$ & 100,00 & $8.207,74$ & 100,00 \\
\hline
\end{tabular}

Fonte: Dados fornecidos pela empresa.

$\mathrm{Na}$ matriz (Recife) as despesas com pessoal em 2008 apresentam maior participação sobre o montante das despesas (60,51\%). Nas filias de Fortaleza e Salvador estas despesas também são as mais expressivas (64,78\% e 59,97\%), respectivamente.

Elaborando-se a análise vertical da matriz e filiais depois da crise (2009), tem-se o seguinte: 
Home Office como instrumento de redução de custos: um estudo de caso realizado na empresa de logística Cargo Company - Recife/PE Antonia Dutra de Araújo, Antonio André Cunha Callado

Tabela 7 - Análise Vertical do mês de janeiro 2009 - (Recife, Fortaleza e Salvador)

\begin{tabular}{|c|c|c|c|c|c|c|}
\hline $\begin{array}{l}\text { DEPOIS DA CRISE } \\
\text { ANÁLISE VERTICAL } \\
\text { PLANO DE CONTAS }\end{array}$ & $\begin{array}{l}\text { RECIFE - } \\
\text { REC } \\
2009 \\
\text { Valor } \\
\text { Absoluto } \\
\end{array}$ & AV & $\begin{array}{l}\text { FORTALEZA - } \\
\text { FOR } \\
2009 \\
\text { Valor Absoluto }\end{array}$ & AV & $\begin{array}{l}\text { SALVADOR - } \\
\text { SSA } \\
2009 \\
\text { Valor Absoluto }\end{array}$ & AV \\
\hline 01.00 - PESSOAL & $46.995,35$ & 55,12 & $5.517,66$ & 48,15 & $1.928,86$ & 70,82 \\
\hline $\begin{array}{l}02.00 \text { - SERVIÇOS E } \\
\text { ASSESSORIAS }\end{array}$ & $5.243,73$ & 6,15 & 750,00 & 6,55 & 380,00 & 13,95 \\
\hline $\begin{array}{c}03.00 \text { - IMPOSTOS E } \\
\text { TAXAS }\end{array}$ & $3.661,66$ & 4,29 & $1.591,79$ & 13,89 & 0,17 & 0,01 \\
\hline $\begin{array}{l}\text { 04.00 - DESPESAS } \\
\text { ESCRITÓRIO }\end{array}$ & $4.299,98$ & 5,04 & $2.108,11$ & 18,40 & 0,00 & 0,00 \\
\hline $\begin{array}{c}05.00 \text { - } \\
\text { COMUNICAÇÃO }\end{array}$ & $2.250,80$ & 2,64 & 971,40 & 8,48 & 338,71 & 12,44 \\
\hline $\begin{array}{l}06.00 \text { - DESP. } \\
\text { FINANCEIRAS }\end{array}$ & $15.964,39$ & 18,72 & 66,00 & 0,58 & 76,00 & 2,79 \\
\hline $\begin{array}{c}07.00- \\
\text { PROPAGANDA }\end{array}$ & 260,00 & 0,30 & 0,00 & 0,00 & 0,00 & 0,00 \\
\hline $\begin{array}{c}08.00 \text { - ADMINIST. } \\
\text { DIVERSAS }\end{array}$ & 925,94 & 1,09 & 453,80 & 3,96 & 0,00 & 0,00 \\
\hline $\begin{array}{c}09.00 \text { - } \\
\text { REPRESENTAÇÕES }\end{array}$ & 176,93 & 0,21 & 0,00 & 0,00 & 0,00 & 0,00 \\
\hline 11.00 - VEÍCULOS & $5.481,49$ & 6,43 & 0,00 & 0,00 & 0,00 & 0,00 \\
\hline TOTAIS & $85.260,27$ & 100,00 & $11.458,76$ & 100,00 & $2.723,74$ & 100,00 \\
\hline
\end{tabular}

Fonte: Dados fornecidos pela empresa.

Os valores absolutos das despesas com pessoal reduziram em 2009 nas filiais. A participação destas despesas na Matriz que eram de 60,51\% em 2008 reduziu para $55,12 \%$ em 2009. Na filial de Fortaleza também houve redução, enquanto na filial de Salvador a participação destas despesas foi superior a 2008.

$\mathrm{Na}$ fase das entrevistas obtiveram-se informações sobre a distribuição de pessoal por setor antes e depois da crise. A distribuição antes da crise pode ser visualizada na Figura 2. 
Home Office como instrumento de redução de custos: um estudo de caso realizado na empresa de logística Cargo Company - Recife/PE Antonia Dutra de Araújo, Antonio André Cunha Callado

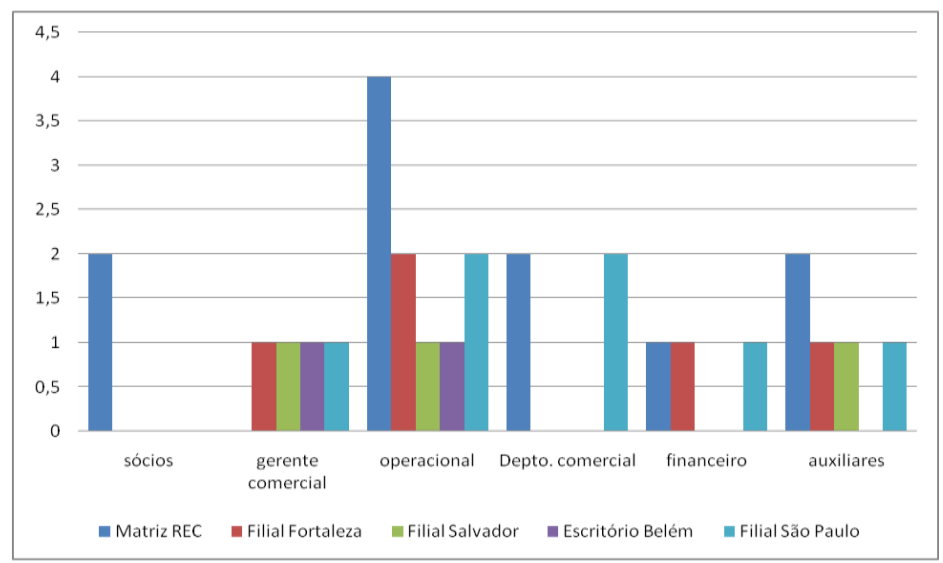

Figura 2 - Distribuição do pessoal por setor (Antes da Crise) Fonte: Dados fornecidos pela empresa.

A distribuição de pessoal depois da crise pode ser observada na Figura 3.

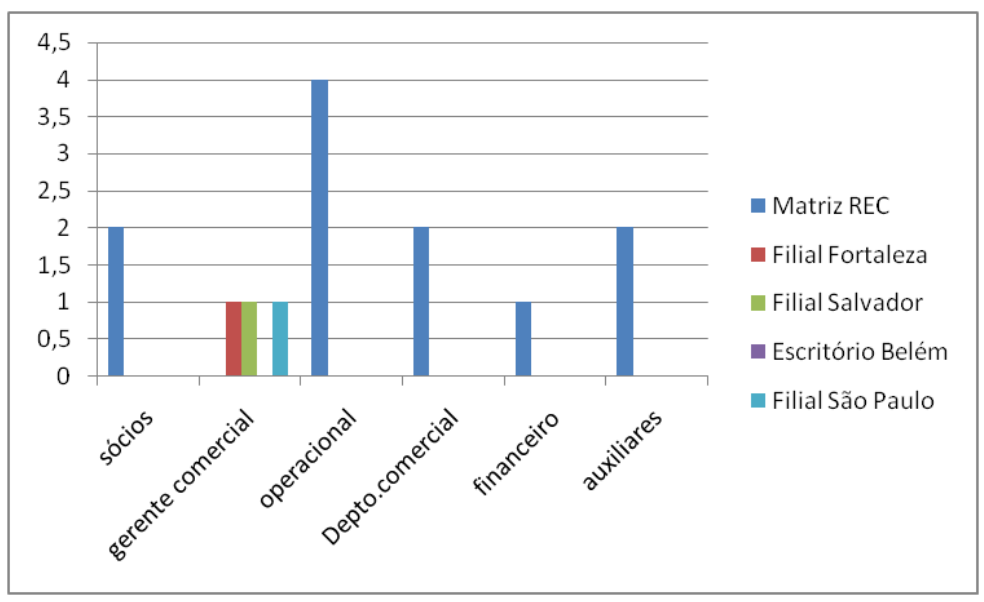

Figura 3 - Distribuição do pessoal por setor (Depois da Crise)

Fonte: Dados fornecidos pela empresa.

Na Matriz em Recife, permaneceu o mesmo quantitativo de pessoal absorvendo as atividades realizadas pelos mesmos setores das filiais; na filial de Fortaleza o pessoal dos setores comercial, operacional e financeiro ficou sob responsabilidade da Matriz; na filial de Salvador o pessoal do setor comercial passou a atuar na forma Home Office e do operacional passou para a responsabilidade da Matriz. No Escritório de Belém fez-se uma parceria com um despachante aduaneiro, sem ônus financeiro; na 
Home Office como instrumento de redução de custos: um estudo de caso realizado na empresa de logística Cargo Company - Recife/PE Antonia Dutra de Araújo, Antonio André Cunha Callado

Filial de São Paulo o encarregado do setor comercial passou a atuar Home Office e as demais atividades foram absorvidas pela Matriz.

Os diretores enfatizaram na entrevista, que numa crise é importante inovar e não ter medo de mudar, o importante é sobreviver ao mercado, mesmo que seja necessário ser ousado ao extremo, porém é importante não extrapolar o risco existente em ações emergenciais.

As análises mostram a importância do controle efetivo das variáveis passiveis de intervenção quando se observam os custos. Outro aspecto observado refere-se à forma como a análise é feita, se realizada profundamente permite identificar se os custos utilizados ou estimados são adequados ou não, o que permite aos gestores intervir de forma a corrigir, quando for necessário.

Observou-se uma grande preocupação na empresa quanto ao controle e execução do processo de registro e armazenamento dos dados das transações, pois os gestores sentiram a necessidade de gerar relatórios relevantes do processo de implantação para melhor conduzir a etapa de transição. Estes aspectos são evidenciados na preocupação que a empresa tem em se manter de forma sustentável e competitiva no mercado.

Os entrevistados deixaram claro o encerramento das atividades das filiais em junho de 2009. Esta previsão pode se estender por motivos legais. Os gerentes serão antecipadamente transferidos para a matriz em Recife. Os custos estimados de Home Office (despesas com administração, pessoal, comunicação, veículo) correspondentes as novas estruturas serão absorvidas pela matriz em Recife.

\section{CONCLUSÃO}

Ao se observar a gestão de custos da Cargo Company - Recife, percebe-se os custos e receitas são tratados em um único centro de custo. Para uma melhor eficiência é necessário que a empresa análise seus custos e receitas por tipo de cliente, segmento de mercado e pelo canal de distribuição. Este procedimento tem como 
Home Office como instrumento de redução de custos: um estudo de caso realizado na empresa de logística Cargo Company - Recife/PE Antonia Dutra de Araújo, Antonio André Cunha Callado

objetivo diminuir os riscos intrínsecos, quando são realizados cálculos em que se usam somente médias.

É necessária a implementação de um método tecnicamente consistente que possibilite a empresa avaliar a rentabilidade dos serviços por ela fornecidos. Até porque a implementação de um método ideal para as necessidades atuais poderá propiciar indicadores que facilitem a alocação dos recursos.

Portanto, é preciso ajustar as técnicas para que a empresa venha a obter informações gerenciais concisas, pois este processo proporcionará aos gestores tomar decisões embasadas em informações com elevado grau de veracidade, evitando erros primários na tomada de decisão.

Com o Home Office tornou-se visível a diferença dos gastos com a estrutura. O que prejudica a avaliação da aplicação do sistema em termos de redução de custo, é que a empresa trata os valores como custos diretos, não realizando o rateio por filiais.

Recomenda-se a intervenção de um especialista na área de gestão de custos para realizar uma auditoria, identificando criteriosamente os pontos falhos, redirecionando a organização para a estabilização da rentabilidade, para que não venha a sofrer entropia positiva.

\section{REFERÊNCIAS}

ABML - Associação Brasileira de Movimentação e Logística. (2009). Disponível em WWW.abml.gov.br.

BALLOU, Ronald H. (1993). Logística empresarial. Rio de Janeiro: Atlas.

Alegre: Bookman. . (2001). Gerenciamento da cadeia de suprimento. (4 ed.). Porto

BARDIN, L. (2002). Análise de conteúdo. Lisboa: Edições 70.

BASTOS, N. T. (1999). Avaliação de desempenho de bancos brasileiros baseada em criação de valor econômico. Revista de Administração, São Paulo, v. 34, n. 3, julho/setembro. 
Home Office como instrumento de redução de custos: um estudo de caso realizado na empresa de logística Cargo Company - Recife/PE

Antonia Dutra de Araújo, Antonio André Cunha Callado

BRANDÃO, H.P.; GUIMARÃES, T.A. (1999). Gestão de competência e gestão de desempenho: tecnologias distintas ou instrumentos de um mesmo construto? In: XII Encontro Nacional da ANPAD, Foz do Iguaçú. Anais... Foz do Iguaçú. CD-ROM.

CARVALHO, José Meixa Crespo de. (2002). Logística. (3 ed.). Lisboa: Edições silabo.

CHRISTOPHER, Martin. (1996). Logística e gerenciamento da cadeia de suprimentos. São Paulo: Pioneira.

. (2001). Logística e gerenciamento da cadeia de suprimentos: Estratégia para a redução de custos e melhoria dos serviços. São Paulo: Pioneira.

COOPER, R.; SLAGMULDER, R. (2004). Achieving full-cycle cost management. MIT Sloan Management Review, v. 46, n. 1, p. 45-52.

DIAS FILHO, J. M.; NAKAGAWA, M. (2001). Decisões sobre planejamento e controle de custos: uma abordagem quantitativa. In: VIII Congresso Brasileiro de Custos, São Leopoldo/RS. Anais... CD-ROM

FARIA, Ana Cristina de. (2003). Custos logísticos: uma abordagem na adequação das informações da controladoria à gestão da logística empresarial. (Tese de Doutorado), Universidade de Economia, Administração e Contabilidade, São Paulo.

HAIR Jr., J. F. et al. (2005). Fundamentos de pesquisa em administração. Porto Alegre: Bookman.

HAMILTON, A. C. (2004). Cost management. AACE International Transactions. Morgantown, p. CSC12.1-12.

HUGHES, Arthur M. (2002). Editorial: The mirage of CRM. Journal of Database Marketing. jan.

KAPLAN, R. S.; COOPER, R. (1998). Custo \& desempenho: administre seus custos para ser mais competitivo. São Paulo: Futura.

MAHER, M. (2001). Contabilidade de custos: criando valor para a administração. São Paulo: Atlas.

MARION, J.C. (2009). Análise das demonstrações contábeis: contabilidade empresarial, 4. ed. São Paulo: Atlas.

MARTINS, Eliseu. (2001). Contabilidade de custos. (8 ed.). São Paulo: Atlas. 
Home Office como instrumento de redução de custos: um estudo de caso realizado na empresa de logística Cargo Company - Recife/PE Antonia Dutra de Araújo, Antonio André Cunha Callado . (1998). Contabilidade de custos: inclui o ABC, (6 ed.). São Paulo: Atlas.

Paulo: Atlas. . (1993). Contabilidade de custos - livro de exercícios. (4 ed.). São

MATTAR, Fauzer Najib. (1994). Pesquisa de marketing, planejamento, execução, análise. São Paulo: Atlas.

NIAZI, A. et al. (2007). A new overhead estimation methodology: a case study in an eletrical engineering company. Journal of Engineering Manufacture, v. 221, n. 4, p.699710.

QUIVY, R.; CHAMPANHOUDT, L.V. (1992). Manual de investigação em ciências sociais. Lisboa: Gradiva.

RICHARDSON, RJ et al. (1985). Pesquisa social - métodos técnicos. São Paulo, Atlas.

RICHARDSON, Roberto Jarry. (Org.). (1999). Pesquisa social: métodos e técnicas. (3 ed.). São Paulo: Atlas.

RYALS, Lynette. (2002a). Are your customers worth more than money? Journal of Retailing and Consumer Services. v. 9, p.241-251.

SANTOS, G. J.; MARION, J. C. (1993). Administração de custos na agropecuária. São Paulo: Atlas.

SEBRAE. (2002). Aprender empreender. Brasília: sala de produções. Disponível em: <http://www.sebrae.com.br/momento/quero_abrir_um_negocio/acesse/biblioteca-online/Resultado_busca_termo_biblioteca?termo_busca=home+office

SELBY, C.; Wilson, C. (2001). Manual do trabalho Flexível. Translation - APDT. Em 29th April. Disponível em: http://www.flexword.eu.com.

SHANK, J. K.; GOVINDARAJAN, V. G. (1997). A revolução dos custos: como reinventar e redefinir sua estratégia de custos para vencer em mercados crescentemente competitivos. Tradução de Luiz Orlando Coutinho Lemos. (8 ed.). Rio de Janeiro: Campus.

SOTKEVICIENE, Elcio José. (2002). Análise da logística aplicada à distribuição física de telefones celulares. 104p. (Dissertação de Mestrado). Universidade Taubaté. São Paulo. 
SOUZA, Alceu.; CLEMENTE, Ademir. (2007). Gestão de custos: aplicações operacionais e estratégias: exercícios resolvidos e propostos com utilização do Excel. São Paulo: Atlas.

TEDLOCK, B. (2005). The observation of participation and the emergence of public ethnography. In: DENZIN, N. K.; LINCOLN, Y. S. The Sage Handbook of Qualitative Research. (3 ed.). California: Sage Publications Inc. p. 474-475.

TRIVIÑOS, A.N.S. (1987). Introdução à pesquisa em ciências sociais. São Paulo: Atlas. $174 p$.

VANDERBECK, E. J.; NAGY, C. F. (2001). Contabilidade de custos. (11 ed.). São Paulo: Pioneira.

$$
\text { Análise de conteúdo. Disponível em: }
$$
http://pt.wikipedia.org/wiki/An\%C3\%A1 lise_de_conte\%C3\%Bado, 21-05-2009 ás 22:25h

YIN, Robert K. (2005). Estudo de caso: planejamento e métodos. (3 ed.). Porto Alegre: Bookman.

Data de Submissão: 14/05/2010

Data de Aceite: 12/04/2011 